In this study 20 children who had measles of the type seen in Europe and North America excreted giant cells for a mean of three days; 20 patients with moderately severe measles with skin staining excreted these cells for a mean of six days; and 14 children with severe measles of the type described by Morley ${ }^{1}$ excreted the cells for 8-29 days (mean 14 days). The severe cases had most of the expected complications-extensive epidermal desquamation, keratitis, stomatitis, and acute enteritis and bronchopneumonia. What was presumed to be the prolonged excretion of virus, as shown by the presence of giant cells, appeared to be related to the severity of the illness, and recovery was associated with cessation of giant cell excretion. There was, as might be expected, a striking difference in the nutritional status of the two groups, the 14 severely ill patients having a lower mean weight than those with mild disease.

Thus one of the main distinguishing features of measles in Africa-namely, the unusual skin changes, with desquamation and extensive mucosal lesions in the mouth and alimentary tract-may be related to prolonged excretion of virus. If so, what are the mechanisms responsible? A simple explanation of the difference between the pathogenesis of "European" and "African" measles is that in the latter an impairment of cell-mediated immunity is associated with protein-calorie malnutrition, as a result of which there is a failure to eliminate virus from the tissues. But this has yet to be proved. It is known that malnutrition is associated with impaired sensitivity to tuberculin and that measles itself leads to a temporary depression of cell-mediated immunity. At present, however, methods of measuring this type of immunity lack the quantitative and qualitative precision of methods available for measuring humoral immunity. Nevertheless it would seem that much has still to be learned about this peculiar disease in terms of the interaction between viral proliferation, malnutrition, and immune mechanisms.

1 Morley, D. C., American Fournal of Diseases of Children, 1962, 103, 230 2 McCarthy, K., American Fournal of Diseases of Children, 1962, 103, 314.

3 Scheifele, D. W., and Forbes, C. E., Pediatrics, 1972, 50, 867.

4 Gresser, I., and Katz, S. L., New England fournal of Medicine, 1960, 263, 452.

5 Beale, A. I., and Campbell, W., fournal of Clinical Pathology, 1959, 12, 335

- Suringa, D. W. R., Bank, L. J., and Ackerman, A. B., New England Fournal of Medicine, 1970, 283, 1139.

\section{Crohn's Disease in the Elderly: A Diagnostic Problem}

For many years Crohn's disease was thought to affect primarily young adults with less than $10 \%$ of all cases presenting over the age of $50.1^{2}$ Lately it has become apparent that the disease has a more uniform age distribution, so that it is almost as likely to develop after middle age as in younger patients. ${ }^{3-5}$ Subsequent epidemiological studies in central Sweden, Aberdeen, and Basle have even suggested that there may be a bimodal age incidence, with a first peak occurring in young adults and the second around the age of 70.6-8 This second peak is mainly due to women suffering from Crohn's colitis. Disease limited to the terminal ileum still tends to affect younger patients. ${ }^{8} \mathrm{~A}$ similar bimodal age incidence has also been described in ulcerative colitis. ${ }^{39} \mathrm{~A}$ current analysis of patients referred to St. Mark's Hospital over the past 20 years confirms that younger people tend to develop disease of the small intestine. ${ }^{10}$ This was true whether or not the colon was also involved, though other workers have reported that ileocolitis, like colitis, shows a bimodal age distribution. ${ }^{8}$ Patients with extensive disease of the colon but without ileal lesions showed a uniform scatter throughout all age groups. However, those whose disease was confined to the distal colon and rectum were usually over 50 .

The recent dramatic increase in the annual incidence of Crohn's disease is largely due to an absolute increase in the numbers of women with colonic involvement, ${ }^{7}$ so that a particular pattern of Crohn's may be expected in the elderly. The patients will mainly be women whose disease is limited to the colon and will often present with an unusual left-sided segmental colitis, a pattern similar to that found in diverticular disease of the colon or, less commonly, in ischaemic colitis. W. A. Hoffman and M. A. Rosenberg ${ }^{11}$ have now described clinical details of four women with Crohn's colitis, three of whom first developed symptoms over the age of 65 . They were all initially thought to have diverticulitis coli and treated accordingly with unsatisfactory and even disastrous results. The message is that Crohn's disease or ulcerative colitis should be considered in the differential diagnosis of elderly patients who complain of diarrhoea, rectal bleeding, abdominal pain, or change in bowel habit. Furthermore, when patients with apparent diverticulitis fare badly after treatment, especially surgical operation, the diagnosis should always be reviewed.

The first problem for the clinician is to reduce the number of cases in which diverticulitis is diagnosed but no diverticula are found on histological examination, the picture being one of pure Crohn's disease. But diverticula are common in the elderly, and so the second problem is to recognize patients in whom the two conditions coexist. G. T. Schmidt and his colleagues ${ }^{12}$ found diverticula in 26 out of 137 cases of Crohn's disease of the colon. In 14 the diagnosis of Crohn's disease was not made before operation, and in four it was not even established by histological study until the resected bowel was re-examined later. The remainder were diagnosed by biopsy of the rectal mucosa or anal lesions. Fortunately certain clinical features may help to distinguish Crohn's disease with diverticula from pure diverticular disease. ${ }^{12} 13$ Though both groups of patients may have pain, diarrhoea, internal fistula, or abdominal mass, the presence of blood in the motions suggests Crohn's disease, especially when the patient persistently passes small quantities. Bleeding in diverticular disease is uncommon, intermittent, and relatively severe. An anal lesion, recto-vaginal fistula, or extra-intestinal complication such as erythema nodosum, pyoderma gangrenosum, finger clubbing, arthritis, or uveitis all suggest Crohn's disease. If sigmoidoscopy discloses proctitis, then diverticulitis is unlikely, though inflammation of the rectal muscosa or pus in the lumen may occasionally be found. Laboratory investigations give abnormal results in both conditions, but rectal biopsy may show features characteristic of Crohn's disease. ${ }^{14}$ Even the presence of non-specific inflammation militates against the diagnosis of diverticulitis. It may prove impossible to differentiate between the two conditions radiologically. Projections of barium may radiate perpendicularly from the bowel limen in both conditions, but they tend to be more irregular, deep, and spiky in Crohn's disease. Other points favouring Crohn's colitis are mucosal ulceration, especially when it involves the rectum or colon at a distance from the 
primary site disease in the sigmoid (skip lesions); disease in an unsually long segment of bowel; and linear confluent intramural ulceration due to a fistulous track running parallel to the bowel lumen. 15

In practice it is important to distinguish between the two conditions. Routine segmental resection of the sigmoid leads to a high incidence of postoperative complications in Crohn's disease. The most common are delay in wound healing, disruption of the anastomosis with fistula formation and discharging abdominal sinuses, recto-vaginal fistula, and chronic anal fissure or fistula. There is also a high incidence of recurrent disease in the remaining colon or rectum, with consequent symptomatic relapse. Correct diagnosis will prevent the complications of inadequate surgical treatment and encourage a more determined course of medical treatment, including the use of corticosteroids.

1 Patter, W. N. van., et al., Gastroenterology, 1954, 26, 347.

2 Crohn, B. B., and Yarnis, H., Regional Ileitis. New York, Grune and Stratton, 1958

3 Evans, J. G., and Acheson, E. D., Gut, 1965, 6, 311.

Monk, M., Mendeloff, A. I., Siegel, C. I., and Lilienfeld, A., Gastroenterology, 1957, 53, 198 .

- Myren, J., et al., Scandinavian fournal of Gastroenterology, 1971, 6, 511.

- Norlen, B. J., Krause, U., and Bergman, L., Scandinavian fournal of Gastroenterology, 1970, 5, 385.

${ }^{7}$ Kyle, J., Gastroenterology, 1971, 61, 826.

8 Fahrlander, H., and Baerlocher, C., Scandinavian Fournal of Gastroenterology, 1971, 6, 657.

- Burch, P. R. J., de Dombal, F. T., and Watkinson, G., Gut, 1969, 10, 277.

10 Lockhart-Mummery, H. E., British fournal of Surgery, 1972, 59, 823.

11 Hoffman, W. A., and Rosenberg, M. A., American Fournal of Gastroenterology, 1972, 58, 508 .

12 Schmidt, G. T., Lennard-Jones, J. E., Morson, B. C., and Young, A. C., Gut, 1968, 9, 7.

11 Lennard-Jones, I. E., Clinics in Gastroenterology, 1972, 1, 367

14 Morson, B. C., New England fournal of Medicine, 1972, 287, 1337.

15 Marshak, R. H., Present, D. H., and Janowitz, H. D., Gastroenterology, $1969,56,1183$.

\section{Kidney Donor Cards}

Wide publicity was given last week to the case ${ }^{1}$ of a $\mathrm{Bir}^{-}$ mingham surgeon who was criticized by the family for removing the kidneys from the body of one of his patients after he had failed in his attempts to contact the parents for permission. This unfortunate episode illustrates the dilemma facing doctors who realize the need for more kidneys to be made available for transplantation. Delay of more than an hour after death before removing the kidneys makes them useless, yet this is the time at which inquiries about the relatives' attitude to the donation of organs can aggravate their distress.

Last year the Department of Health began a campaign ${ }^{2}$ for more kidney donors and issued a "kidney transplant donor card" which could be carried by any member of the public who was willing that his kidneys should be used after ceath. The card, signed by the bearer with the agreement cf his next of skin, gives a doctor all the legal permission he needs to remove the organs after death has occurred. So far about 2,000,000 cards have been issued; but many doctors still seem unaware of their existence, though they are available free of charge from the Department of Health. If every doctor's waiting room and every hospital outpatients department had a stock of cards on display surgeons would be sfared the unpleasant task of having to discuss permission for operation from relatives at the moment of their bereavement.

1 Daily Telegraph, 17 July 1973.

British Medical fournal, 1972, 4, 500.

\section{Uncertain Metamorphosis}

In the late 1950s public health doctors failed to persuade the Government to include them in the terms of reference of the Royal Commission on N.H.S. doctors' and dentists' pay. ${ }^{1}$ Thus they were shut out at the start from the N.H.S. doctors' pay review machinery. The impending reorganization of the Health Service has ended their exclusion. Whether the outcome of the Review Body's first assessment of their worth ${ }^{2}$ (Supplement, p. 11) will be to the liking of the 1,000 or so senior medical staff transferring from local government to the N.H.S. next April is doubtful. Many will be frankly disappointed, for in assessing the top fosts of medical officers in regional and area authorities the Review Body has proposed salaries some way below the B.M.A.'s demands. The report recommended $£ 10,248$ against nearly $£ 13,000$ for top-of-the-scale regional medical officers and $£ 9,354$ against over $£ 10,000$ for similarly placed area medical officers. On the credit side the Review Body bas accepted that the career grade for the specialty of community medicine should be "broadly equivalent to that of consultant and carry a similar salary scale." Furthermore, the report's proposals should enhance the financial prospects for many hospital medical administrators-there are nearly 200 of them altogether-who will also be joining the new specialty.

Lord Halsbury and his colleagues had no easy task, despite the B.M.A. and the Health Departments submitting much of the evidence jointly. Firstly, recommendations had to be made against the background of an incomes policy. This meant a careful comparison between what doctors in a row specialty will be doing in an unfamiliar situation in 1974 and the work their antecedents were doing in 1973-and fublic health was largely unknown territory to the Review Rody's members. Secondly, the Review Body had to make its recommendations in haste, since the new posts had to be advertised quickly; and yet the start of the review was delayed by the profession's difficulties in deciding how community medicine should fit into the existing N.H.S. medical pay structure. ${ }^{3}$ So it is hardly surprising that the Review Body admits to proceeding "with caution" and describes its recommendations as provisional.

In their two joint statements of evidence the profession and the Departments explained the present structure and functions of public health as well as what they envisaged would be the "job specification" of specialists in community medicine. Inevitably some of the work will be as before. Local health authorities will still need advice on environmental health, which will be obtained through the medium of "seconded" area health authority doctors ${ }^{4} \longrightarrow$ presumably they will be community medicine specialists. Epidemiology will continue to be an important function, and the work of planning district, area, and regional health services will be an extension of existing activities. The School Health Service will be transferred to the N.H.S. and the work of its medical staff will presumably be broadly as at present. As a result of the Seebohm legislation most public health doctors have been relieved already of their social work responsibilities, a point the Review Body makes in explaining why it has not matched the top local authority medical salaries.

Summarizing the differences between the present and future rosts the B.M.A. and Health Departments see the regional medical officer carrying out most of the functions of the S.A.M.O. "but over a wider field." This will be so 